\title{
What could happen when action research meets ideas of sociomateriality?
}

\author{
Stephen Allen and Judi Marshall
}

Published in International Journal of Action Research 2019_299-112

https://doi.org/10.3224/ijar.v15i2.02

\begin{abstract}
Action research in its various forms highlights the interactional and relational ways in which research and knowledge become socially produced with people, with intentions of positively transforming real-world relations. In parallel, there is a growing interest in organizational research informed by the field of Science and Technology Studies, about the potential significance of matter to understanding how processes of researching interact with the world. By experimenting with connections to debates about sociomateriality, this paper explores what implications there might be for understanding and performing action research, especially given that action researchers are often values-oriented and attached, and acknowledge that they want to change material issues.
\end{abstract}

Key words: action research, affordance, matter, sociomaterial, sustainability

\section{Introducing attentions and purposes}

Action research involves coproducing knowledge and action to positively transform real-world relations (e.g. Bradbury 2015; Cooke \& Wolfram Cox 2005). This article considers how debates in the field of Science and Technology Studies (STS) (e.g. Barad 2007, 2013; Law 2004; Orlikowski \& Scott 2008) can help to develop a perspective of action research as materially as well as socially (co)produced. In particular, we draw on the concept of 'affordances' (Bloomfield, Latham, \& Vurdubakis 2010; Hutchby 2001; Jarzabkowski \& Pinch 2013) to explore how action researchers can be critically and reflexively aware of ways that sociomaterial relations can shape possibilities for action.

This paper is offered in the service of fostering organizational and societal change for sustainability. We understand action on sustainability is imperative so that future generations of humans and nonhuman species can flourish together on the Earth. At these times of, to us, profound environmental crisis (e.g. IPCC 2018; Steffen et al. 2015), we are acutely aware of the limitations of offering yet another damned journal article. But we find articles valuable when they prompt us to feel surprised about aspects of being and researching that we might have taken-for-granted, making us pause to consider other possibilities for action. So, by developing a sociomaterial perspective we want to attempt to extend visibility on the significance of matter to the relations involved in action researching.

We believe that developing a sociomaterial perspective is vital for action researchers, particularly those who are values-oriented and attached, as material relations matter. We assume that paying attention to emergence and interdependence are crucial for creating change with integrity, which means that action researching requires systemic ways of thinking, acting and being (Burns 2007; Flood 2010; Marshall 2016; Wilson, Walsh, \& Bush 2018). Consequently, sociomateriality can offer possibilities for action researchers to develop congruent ontologies which are defined by relationality and interconnectivity, because we cannot change the world without transforming and being transformed by matter. How we make and reproduce 'boundaries' between ourselves and matter is a fundamental concern (Midgley 2000). We are responsible to matter, especially in connection with climate change and loss of biodiversity. By understanding matter as active in creating our understanding, and so significant for fostering critical action, we hope to help to enrich debates about implications of sociomaterial relations in action researching. 


\section{Positioning contributions within action research debates}

Action research is a 'family' label applied to a richly diverse range of approaches (Bradbury 2015; Cooke \& Wolfram Cox 2005; Reason \& Bradbury 2001, 2008). Whilst there is no one 'it', we are drawn to key characteristics in formulations of action research which foreground being in the service of human and ecological flourishing.

In a seminal contribution to action research debates, Reason and Torbert describe an 'action turn' in social research generally as involving a need to develop knowledge that relates to "a practical knowing embodied in the moment-to-moment action of each researcher/practitioner" (2001, p. 7). This turn or paradigm is positioned as contrasting significantly with an academic tradition that aims "to contribute to an abstract 'body of knowledge' available to third-persons" (Reason \& Torbert 2001, p. 7).

Action research intends to produce knowing in and through action with others which is thoroughly embodied as well as propositional (Heron \& Reason 1997). A core idea is that everybody involved is treated as an active agent in producing the research. Those involved make sense of their world and their practice by inquiring collaboratively to generate theories and insights (Kemmis 2008; Reason 1999). As Reason and Torbert describe:

$[\mathrm{H}]$ uman knowing after the action turn is essentially participative, growing from collaborative relations with each other as co-inquirers into our world; and in addition, since human persons and communities are a part of the larger cosmos, all knowing is grounded in participation in the wider ecology of living and non-living things. (2001, p. 7; our italics)

This participative and systemic view of the world sees acting and knowing as arising through our relational embeddedness with humans and nonhuman species and entities, i.e. social and material relations. However, whilst the action research literature shows considerable interest in understanding relational and power dynamics amongst communities of people pursuing action (e.g. Janes 2016; Ravn Olesen \& Nordentoft 2016), there has been limited attention to the ways in which material arrangements, within which and through which these social dynamics take place, could be significant to action. Consequently, by drawing on ideas of sociomateriality, and in particular 'affordances', the contribution of this paper is to consider more fully the potential implications of understanding action research as "grounded in participation in the wider ecology of living and nonliving things" (Reason \& Torbert 2001, p. 7).

\section{Writing form and content}

The format of this paper reflects the pattern our conversations took as we developed our ideas about the possible meanings and implications of a sociomaterial perspective for action research. Proposing insights from sociomateriality that might be relevant for action research felt like the breaking of a wave lapping up the beach, over-riding, spreading out. However, had we left our thinking there, we were not doing due justice to the potential shadow sides of what we were proposing. A next phase of our conversation was more nuanced, asked questions, softened our advocacy, had a feeling of pulling back from over-strong assertions, as a wave recedes back down the beach. We then reviewed where this took us, what was left on the beach. We have sought to show this formatting here. The article thus shows its emergence, acknowledging questions and dilemmas as we write, rather than seeking to resolve them, intending dialogue between action research and sociomateriality. It adopts the form of two waves of proposing ideas followed by reflexive recessions, with a final section that brings together some closing reflections.

This article is itself intended as an inquiry, seeking to connect with fellow scholars engaged in action research and with concerns about sustainability. We have inquired together through cycles 
of writing and reflection (Heron \& Reason 2008), but we have not figured out the action implications of bringing these ideas and action research practices together. Our intention here is to share speculative thinking, as a step towards envisaging grounded practice.

\section{Wave 1 - Bringing in (socio)materiality}

surge.... swell.... as the wave rushes up the beach, with impressions to offer....

\section{"Humans' do not simply assemble different apparatuses for satisfying particular} knowledge projects but are themselves specific local parts of the world's ongoing reconfiguring" (Barad 2003, p. 829).

Interdisciplinary debates within STS challenge taken-forgranted ideas about how we can know what to do (Felt, Fouché, Miller, \& Smith-Doerr 2017). Knowledge making is understood to be an embodied process. STS provocations challenge constructions of human 'subjects' as active, knowing and influencing, and material 'objects' as passive, knowable and formable (Law 2004).

Matter is not 'an inert canvas' of passive objects which are organized by social processes (Barad 2007, 2013). Nor is it "some thereness available for the taking, a mere backdrop to what really matters" (Barad 2013, p. 17). Matter is "a doing, a congealing of agency. It is morphologically active, responsive, generative, articulate, and alive" (Barad 2013, p. 17). Matter matters because "it generates consequences for how we experience and act in our world" (Carlile, Nicolini, Langley, \& Tsoukas 2013, p. 4). Thus, "humans are part of the material world, not transcendent gods or magicians able to manipulate the material without being incorporated or changed by it" (Dale \& Burrell 2008, p. 210).

Sociomateriality connects the social and material by understanding that they are only defined and produced by their interaction (Jones 2013). The metaphor of human entanglement helps understand the implications of being interactively part of a sociomaterial world (Orlikowski 2007). "Humans are constituted through relations of materiality - bodies, clothes, food, devices, tools, which, in turn, are produced through human practices" (Orlikowski 2007, p. 1438). The skin is "not an impermeable boundary but a permeable zone of intermingling" where "every organism - indeed, every thing - is itself an entanglement" (Ingold 2008, p. 1806). "We do not obtain knowledge by standing outside of the world; we know because 'we' are of the world" (Barad 2003, p. 829). Any human practice "will necessarily involve the material bodies of the participants, located in a particular material context, so there can be no social that does not involve the material" (Jones 2013, p. 213). There are no independently existing entities with inherent characteristics. The social and material are mutually constitutive.

Researchers are entangled within research communities which are bound up in material practices of knowledge making (Latour 1987; Law 1994). Materials used in practice (e.g. technologies, artefacts and tools) have an active role in shaping the actions and routines of knowledge production. For example, fossil energy resources power aeroplanes, spurring researchers to travel further. Computer algorithms shepherd researchers' literature searches, helping delineate inclusion, exclusion and boundaries of perceived relevance. 
STS languages offer enticing possibilities for broader attention, but how action researchers can work with these often esoteric ideas is challenging. In the few papers which already attempt sociomaterial interpretations of action research initiatives (Allen, Brigham, \& Marshall 2018; Suopajärvi 2017), sociomateriality is drawn upon as part of retrospective analysis. Allen, Brigham and Marshall (2018) analyse their participation in an urban regeneration initiative, which had a vision to be environmentally sustainable, by taking a sociomaterial lens to explore how building and facility management arrangements (including legal contracting processes and computer systems) can be understood as having significant agency in shaping the boundaries for what sustainability could become. Suopajärvi (2017), by completing an ethnographic analysis alongside action research workshops about ageing, attempts to notice the potentially active role of non-human agents such as the physical meeting space (e.g. furniture) and artefacts (e.g. a magazine brought in by a participant) in shaping the processes and outcomes of the research.

We realise that action researchers are working across territories of action and expertise. In the grounded realm of practice, we expect more openness to sociomaterial sensibilities, for example in how environments are shaped and engagements enacted to empower co-inquirers (Gaventa \& Cornwall 2015). We wonder if nuanced experiencing and noticing of relations with matter can be readily articulated as researchers seek to publish their work. We suspect that fine-grained engagement with matter might be discounted in the rubrics of what counts as acceptable knowing, potentially considered too banal. For example, detailed care in relation to repeatedly writing up, formatting and circulating notes during a collaborative inquiry might become a footnote under 'Research Methodology'. Legitimating action research in the academy could risk losing, and thus not communicating to developing researchers, this wider realm of being, however much we aspire to live with multiple forms of knowing. Does STS offer languages for helping to develop and maintain sociomaterial attentions?

Much of the work associated with STS tends to be related to studies of scientists (e.g. Law 1994) and technologies (e.g. Orlikowski 2007). Whilst science and technology are used as multifaceted terms joining us with a world, coevolving socio-cultural 'nature' in the flow of knowing and being is not focal. For example, human settlements can often be understood to be substantially organised by the physical landscape, such as growing from proximity to rivers for water and transportation. So when the river dries up due to changing climates the settlement likely disappears, such as is suggested about some 'lost cities' of ancient worlds (Zalasiewicz, Williams, Steffen, \& Crutzen 2010). Now the rights to personhood of rivers, such as the Colorado, are being legally claimed in attempts to prevent hydraulic fracturing (Turkewitz 2017). Consequently, if we are to adopt a sociomaterial perspective for action research we need to pay attention to the interactive material consequences, beyond being in dialogue with other people, to the ground that we walk on, the air that we breath, and the water we drink.

Perhaps some action researchers are already being attentive to matter, and do not need the languages STS offers. For example, Pimbert and Wakeford (2003) pay explicit attention to material issues in their research methods and care is taken to work against social power disparities in how forums for co-working are set up to form visions about local futures for food and farming. Pimbert and Wakeford supported the development of citizens' juries - the people sat as a panel, and 'experts' in agriculture came before them to offer their views, reversing pervasive dynamics in which receivers of aid are placed physically and intellectually as supplicants.

We suggest that engaging explicitly with ideas from STS offers action researchers opportunities to develop further and explicate their sociomaterial perspectives and sensibilities, and embodied action. However, examples tend to become about matter's usefulness to humans, turning matter into tools (e.g. shale gas as an energy source), and so inadvertently bring in neopositivist ideals that we know, are separable from, and can control matter. Helpfully illustrative as (simple) examples are, such as understanding 'natural' landscapes as informing human settlements, do they 
tend - and encourage us - in this direction? But materiality is more than that.

We are interested to consider if and how sociomateriality can be further integrated into the processes and practices of doing action research. In the current world of climate change, loss of biodiversity and mass extinction these are fundamental issues. If a deep respect for matter's right in its own right is held by action researchers, sociomateriality offers another language, sensibilities and legitimacy for articulating those intents and practices. This is likely a different direction than academic aims of action research, which can include gaining legitimacy through publication in journals considered prestigious (to avoid being seen as a 'niche' research approach).

receding... ebbing... backwash ... depositing some things, taking others away... residue... the beach reshaped in dynamic interaction

We appreciate the surge and excitement that STS ideas about sociomateriality can offer us to reflect upon our action researching. So far we notice two particular strands. Firstly, we are attentive to how our entanglements with matter shape our knowing. For example, as mentioned above, collaborative inquiry notes are not only derivative, a reflection of human conversation, but are also mutually constitutive of ongoing action. Notes circulated by email may not reach or be accessible to some coresearchers. Their 'absence' too is potentially significant. We require a different sensibility about such activities, so that a different sense can be made. Dwelling with notes from inquiry meetings, we could pay attention to how they are circulated. Does the account include pictures? What material consequences will the formatting choices have, in terms of toner and paper requirements if the account is printed?

Secondly, we notice a strand about developing respect for the rights of matter, rather than matter being used flagrantly and hurriedly in the service of efficiency and convenience in humanonly terms. For example, if only one hour is allowed for a meeting, and no-one wants to engage with the politics of who makes coffee - and washes up - these days, in the UK, a cluster of one-use cups and plastic lids may be left behind at the end. How can we interact with sufficient levels of material engagement and respect?

The next wave attempts to elaborate on these strands, and develop others. The concept of 'affordance' seems especially fruitful for extending and developing a sociomaterial perspective in action research. In the history of action research debates, sociomaterial ideas such as Actor Network Theory have had some marginal explicit and tacit influence, but limited or no connections seem to have been made in action research to the notion of 'affordance'.

\section{Wave 2: Affordances in sociomaterial relations}

surge.... swell.... as the wave rushes up the beach, with impressions to offer....

"Far from being inscribed upon the bedrock of physical reality, meaning is immanent in the relational contexts of people's practical engagement with their lived-in environments" (Ingold 2002, p. 168)

An affordance is about understanding the action possibilities that our interactions with matter affords us. Affordances refer to how "specific action unfolds in that unique moment and situation, whom and what it enrolls, and how it affects the world" (Faraj \& Azad 2012, p. 255). Affordances help to bring sociomaterial appreciations to understanding (in)actions.

Perceptual activity involves "the movement of the whole being (indissolubly body and mind) in its environment", "to perceive what it 
affords" (Ingold 2002, p. 166). "Knowledge of the world is gained by moving about in it, exploring it, attending to it, ever alert to the signs by which it is revealed" (Ingold 2002, p. 55). Learning is about an embodied 'education of attention' to be able to engage with human and non-human, animate and inanimate (Ingold 2002).

Affordances offer possibilities to deal with issues of 'undersocialized and oversocialized' ways of understanding human and non-human sociomaterial interactions (Bloomfield et al. 2010). Affordances are relational. The dynamics enabling and constraining action differ between beings and contexts, e.g. "water surfaces do not have the affordance of walk-on-ability for a lion or a crocodile, but they do for an insect waterboatman" (Hutchby 2001, p. 448).

Affordances "are not reducible to their material constitution but are inextricably bound with specific, historically variable, ways of life" (Bloomfield et al. 2010, p. 428). Any object can afford various action possibilities in the social context of its use. For example, a bag could afford "a cheap and effective drinking vessel in Asia, fashioning a medical device in an emergency, or making a Halloween mask for a children's party" (Jarzabkowski \& Pinch 2013, pp. 587-588).

Bringing attention to how matter interactively shapes action possibilities opens up questions about how affordances are sustained and can be challenged. Can we explore and represent how "the body comes to grant particular affordances to the (made) world and conversely, the world comes to be 'mirrored' in the ... action capabilities of the body" (Bloomfield et al. 2010, p. 429)? How can we come to appreciate the assumptions and social obligations which hold sociomaterial relations in place (Jarzabkowski \& Pinch 2013)?

friction... breaking.... swash .... initial surge is interrupted ... breaks apart... spreads out.... intermingles....

Taking a relational view of affordances, i.e. avoiding essentialising and undersocialising viewpoints, offers potential to develop a sociomaterial perspective for how 'action possibilities' emerge for action researchers moving within and with environments, artefacts and technologies.

We are curious about what is involved in bringing notions of sociomateriality more to the fore in researchers' ongoing thinking and action. The concept of 'affordances' is enticing to help to work towards a richer way of understanding the potential implications of a sociomaterial perspective for action researching. Affordances brings a dynamic orientation to action possibilities which can heighten attention to noticing how materials can shape and be shaped through social interacting. However, these are not simply functional interactions such as the possibilities for using materials in different ways in action, but inescapably relational and situated within historical socio-cultural evolutions. What this implies is that the social meanings given to materials and the skills needed to be afforded interaction are bound up in evolving differentiated power relations, such as gendered practices (e.g. a man feeling a need to open a door or carry a 'heavy' bag for a woman). How could greater attention be brought to the participatory dynamics of what matter affords of you and the possibilities for what you can afford of it?

In affordance terms the (natural-artificial) physical environment affords different peoples' bodies differing action possibilities or capabilities, such as the example above where water affords different possibilities for different types of animals. This could be about peoples' skills or strengths, such as being challenged by their bodies' mobility and how the ways the physical environment is constituted and construed shapes movement and the meanings of (non)movement, as well as how those movements relate to others' bodies, and the varying social values and identities placed on the ways people move themselves and objects.

An example (based on one author's experience) of meeting with people to talk and eat together can be explored with a sociomaterial lens to prompt critical and reflexive questions about 
how (in)action possibilities emerge. This example, which was not part of 'formal' processes of action researching, took place among the organisers and speakers the evening before an academic symposium. The meeting place, a pub, was chosen due to its unique significance of being understood as the oldest public building in the city where the symposium was taking place, in the North of England. The table for dinner was located on the first floor, a space afforded only to bodies able to be navigated up winding stairs. Bondings of the place 'pub' with collective alcohol consumption, renders possibilities of non-alcoholic refreshment 'atypical' and potentially open to question. The food on offer enrolled and afforded many possibilities for meat and fish eaters, but little opportunities for a plant-based meal. Lastly, the walk home late in the evening through a quietening city centre afforded movement possibilities for people who would feel that space to be unthreatening, and whose bodies others would read as unapproachable.

From this example, we can consider how sociomaterial interactions which produce meeting places can shape possibilities for action. A place to meet is chosen based on its historical significance and connected potential appeal to visitors. This selection of place, whilst apparently banal, can be consequential to the action possibilities which can emerge. Some potential participants in the talking and eating together might be repelled by the imagined space they will encounter and their anticipated inability to dwell within it, as well as to navigate to and away from it. Those who do 'go to the pub' are enrolled into a certain range of eating and drinking possibilities, which may discomfort and disconnect some people, as well as help to keep others tightly enrolled in eating practices (such as high meat intake) which have negative environmental consequences (e.g. Hedenus, Wirsenius, \& Johansson 2014).

For action researchers seeking to bring bodies together and foster ways forward on issues of collective concern, not being attentive to sociomaterial dynamics involved in meeting together, means ideals of 'multiple perspectives' and 'diversity of voices' can become naively claimed. In other words, the materialities of being together are bound up in exclusions and inclusions of certain problematic social relations (e.g. relating to gender, wealth, race, disability, sexuality) which may be counter to the emancipatory intentions hoped to be addressed through action research, such as engaging with marginalised immigrant communities, or disenfranchised young people.

How the dialoguing in support of action comes from within particularly constituted and understood spaces is potentially important to any participatory unfoldings. These interactions could be mundane and unnoteworthy but may have significance to action possibilities. Indeed, attempting with other to re-see aspects of the physical environment, and the significance for movement and action, and for matter's intrinsic rights, could be productive for opportunities to influence change. For example, seeking to prompt action associated with averting ecological destruction from within pampered, windowless and air-conditioned surrounds could be disruptively disembodying, dulling and dumbing relevant sensibilities. What might be different about conversations held in a tent, in the rain, with (congruent) toilets along the path?

receding ... ebbing ... backwash ... depositing some things, taking others away ... residue... the beach reshaped in dynamic interaction

The concept of affordances can help us to consider the sociomaterial dynamics which are involved in the action possibilities which do and do not emerge as we seek to positively transform real-world relations. Affordances could help to add to the multi-dimensionalities of attention and knowing adopted by action researchers by bringing greater visibility to the participatory dynamics of what matter affords of us (e.g. enabling or disabling entry of different bodies into spaces to meet together), and the possibilities for what we can afford of matter (e.g. perpetuating or interrupting patterns of consuming and conserving certain foods and drink).

We glimpse the potential to understand relationships as grounded in mutual communion (Bakan 1966; Marshall 1984), a coevolving and interdependence of social and material in which the person-researcher is indelibly entangled in multifarious and multidirectional responsibilities. However, using the notion of affordances in a truly relational manner is challenging. As STS writers 
have noticed there can often be a need to split social and material to make sense of and communicate our research involvements (Faraj \& Azad 2012). Consequently, we do need to be aware of how language categorises and bounds people and things and seek to act and write in critical and reflexive ways that engage with sociomaterial entanglement (e.g. Allen 2019).

\section{Closing reflections}

We began this article suggesting that we wanted to develop a sociomaterial perspective which could prompt us and other action researchers to feel surprised about aspects of being and researching that we might have taken-for-granted, making us pause to consider other possibilities. Our inquiry and writing are in the service of sustainability. The article's formatting of waves has tried to keep things open and has allowed us, we think, glimpses of possibilities. For now, we accept the unfinished quality of the perspective that we offer and seek to notice some momentary contours of the 'beach' before another wave arrives. We can particularly identify two themes running through our attempts at examples which can add texture to the perspective we are attempting to offer.

Firstly: human inclusion or exclusion as mediated by material circumstances. Although connected examples come somewhat readily to mind (e.g. the places and spaces of meetings, and information communication technologies patterning our interactions), we risk treating matter as a tool for human intentions. Also, in writing, language has been challenging, so predicated as it is on human subject and distinguishing material world as 'object', and potential tool. We seek appropriate language as well as sensibilities, to conceive of, and write about, our engagements with more material respect and communion. Can we appreciate entangled ways of being by reaching beyond dualist notions that encourage subject-subject or subject-object thinking? We wonder if influences such as Robertson's (1990) principles for an economy for the $21^{\text {st }}$ Century of enabling and conserving could be part of helping develop our perspective. We are also aware that action research likely has offerings to make to STS sensibilities through its attentions to subtle dynamics involved in participation and emancipation.

Secondly: compressions in time as a significant cultural patterning, focusing (rather than contextualising) perception and shaping behaviour. Notions of time efficiency and subsequent hurry seem to make matter more dispensable. They also constrain and rush human bodies, encouraging stress reactions. Slower movement is likely to be less energy intensive, and more humane. However, examples indicating alternative possibilities can seem trivial, and too highly focused. Why pay attention to the use of toner in a print cartridge, when the room, the lighting, the printer (and its replacement regime), and the paper are all normalised? Additionally, the moment we place certain ways of working and being as socially and/or ecologically more congruent with values we might seek to uphold we can lose a sense of how everything is produced and afforded within specific constellations of sociomaterial relations. For example, a circumstance of a cyclist who mainly gains sustenance from airfreighted vegetables reconfigures a low intensity mode of travel. Hence we need to be attentive to how we might craft positions and inadvertently pin 'things' down.

Wanting to share our inquiry with others at this preliminary stage of thinking, we have favoured speculative openness, wanting to stay metaphorically close to the ground. Two images have then arisen about how to continue to think about these issues. Firstly, sociomaterial inclusion seems, perhaps, more possible when experiences and 'things' are kept malleable/ pliable/ multidimensional and are not too pinned down. Secondly, empathising with a tent in the rain as a congruent place to consider sustainability we realise we are pulling against thinking becoming abstracted, with associated implications of 'better', more generalisable, less attached; for example in scenario planning considering alternative futures. Do we need a procedural form of biomimicry, grounded, entangled, in touch with matter? It is in this territory of action research, with radical participation at its heart, in which we hope a sociomaterial perspective can emerge.

If we critically turn a sociomaterial lens on our action we do see shadow sides to our efforts to produce this article. The matter of this article is consequential to sustainability. We may have 
worked together without needing to burn fuels to travel to meet to develop the writing. However, the servers and datacentres which enable the internet connectivity of our video calls, screens and computer processers require electrical power with various associated emissions (e.g. Berners-Lee 2011). Anybody who wants to read this article online requires similar technologies and electrical power. Such computing technologies contain metals like tin and tantalum whose mining and extraction can involve socially and ecologically exploitative processes (e.g. Simpson 2012). Additionally, the assembly of some computer devices have been connected with disastrous labour processes (e.g. Moore 2012), and excessive executive pay (e.g. Colt 2015). This is just a brief glimpse of our sociomaterial entanglements in aspects including validating publishing as valuable academic work, reinforcing certain information and computer technologies as essential, accepting problematic trading and production arrangements for metals, and being complicit with processes of extreme capital accumulation. These patterns of relations afford the possibility of the publication of this article in an academic journal.

Living and researching responsibly, within the perspective we have suggested, inevitably requires action researchers to attempt to avoid or subvert a multitude of sociomaterial relations, whilst seeking to create values-based alternatives. Understanding ourselves as upholding what we value in times of palpable human unsustainability without becoming too overwhelmed in the imagined contradictions can be challenging. Our collective entanglements unavoidably cast long and complex shadows, as we indicated above. However, if we want to strive for positive change, seeking to commune with a wider ecology of living and 'non-living' things is core to our action researching.

\section{References}

Allen S. (2019). The Unbounded Gatherer: Possibilities for posthuman writing-reading. Scandinavian Journal of Management, 35(1), 64-75.

Allen S., Brigham, M., \& Marshall, J. (2018). Lost in delegation? (Dis)organizing for sustainability. Scandinavian Journal of Management, 34(1), 29-39.

Bakan D. (1966). The Duality of Human Existence. Boston: Beacon Press.

Barad K. (2003). Posthumanist Performativity: Toward an Understanding of How Matter Comes to Matter. Signs: Journal of Women in Culture and Society, 28(3), 801-831.

Barad K. (2007). Meeting the universe halfway: Quantum physics and the entanglement of matter and meaning. Durham \& London: Duke University Press.

Barad K. (2013). Ma(r)king Time: Material Entanglements and Re-memberings: Cutting TogetherApart. In P. R. Carlile, D. Nicolini, A. Langley, \& H. Tsoukas (Eds.), How Matter Matters: Objects, Artifacts, and Materiality in Organization Studies. Oxford University Press.

Berners-Lee M. (2011). How bad are bananas?: the carbon footprint of everything. Greystone Books.

Bloomfield B. P., Latham Y., \& Vurdubakis T. (2010). Bodies, technologies and action possibilities: When is an affordance? Sociology, 44(3), 415-433.

Bradbury H. (Ed.). (2015). The Sage handbook of action research (3rd ed.). London: Sage.

Burns D. (2007). Systemic Action Research: A Strategy for Whole System Change. Bristol: Polity.

Carlile P. R., Nicolini D., Langley A., \& Tsoukas H. (Eds.). (2013). Introducing the Third Volume of "Perspectives on Organization Studies". In How Matter Matters: Objects, Artifacts, and Materiality in Organization Studies. Oxford University Press.

Colt S. (2015, January 23). Here's How Much Apple's Top Execs Made Last Year. Retrieved 7 September 2018, from http://uk.businessinsider.com/heres-how-much-apples-top-execsmade-last-year-2015-1

Cooke B., \& Wolfram Cox J. (Eds.). (2005). The Fundamentals of Action Research (Vols 1-4). London: Sage Publications.

Faraj S., \& Azad B. (2012). Materiality and Organizing: Social Interaction in a Technological 
World. In P. Leonardi, B. A. Nardi, \& J. Kallinikos (Eds.), The Materiality of Technology: An Affordance Perspective. Oxford University Press.

Felt U., Fouché R., Miller C., \& Smith-Doerr L. (Eds.). (2017). The Handbook of Science and Technology Studies, Fourth Edition. Cambridge, Mass.

Flood R. L. (2010). The Relationship of 'Systems Thinking' to Action Research. Systemic Practice and Action Research, 23(4), 269-284.

Gaventa J., \& Cornwall A. (2015). Power and Knowledge. In H. Bradbury (Ed.), The Sage Handbook of Action Research (3rd ed., pp. 465-471). London: Sage.

Hedenus F., Wirsenius S., \& Johansson D. J. (2014). The importance of reduced meat and dairy consumption for meeting stringent climate change targets. Climatic Change, 124(1-2), 7991.

Heron J., \& Reason P. (1997). A Participatory Inquiry Paradigm. Qualitative Inquiry, 3(3), $274-294$.

Hutchby I. (2001). Technologies, Texts and Affordances. Sociology, 35(2), 441-456.

Ingold T. (2002). The perception of the environment: essays in livelihood, dwelling and skill. London: Routledge.

IPCC. (2018). Global Warming of $1.5^{\circ} \mathrm{C}$ : An IPCC special report on the impacts of global warming of $1.5^{\circ} \mathrm{C}$ above pre-industrial levels and related global greenhouse gas emission pathways, in the context of strengthening the global response to the threat of climate change, sustainable development, and efforts to eradicate poverty. Geneva, Switzerland: IPCC. Retrieved from http://www.ipcc.ch/report/sr15/

Janes J. E. (2016). Democratic encounters? Epistemic privilege, power, and community-based participatory action research. Action Research, 14(1), 72-87.

Jarzabkowski P., \& Pinch T. (2013). Sociomateriality is 'the New Black': accomplishing repurposing, reinscripting and repairing in context.M@N@Gement, 16(5), 579-592.

Jones M. (2013). Untangling Sociomateriality. In P. R. Carlile, D. Nicolini, A. Langley, \& H. Tsoukas (Eds.), How Matter Matters: Objects, Artifacts, and Materiality in Organization Studies. Oxford University Press.

Kemmis S. (2008). Critical theory and participatory action research. In Handbook of Action Research. London: Sage.

Latour B. (1987). Science in action: how to follow scientists and engineers through society. Cambridge, Massachusetts: Harvard University Press.

Law J. (1994). Organising Modernity. Oxford: Blackwell.

Law J. (2004). After method: mess in social science research. Abingdon: Routledge.

Marshall J. (1984). Women Managers: Travellers in a male world. Chichester: John Wiley.

Marshall J. (2016). First Person Action Research: Living Life as Inquiry. London: Sage.

Midgley G. (2000). Systemic intervention. London: Kluwer.

Moore M. (2012, January 11). 'Mass suicide' protest at Apple manufacturer Foxconn factory. Retrieved from https:/www.telegraph.co.uk/news/worldnews/asia/china/9006988/Masssuicide-protest-at-Apple-manufacturer-Foxconn-factory.html

Orlikowski W. J. (2007). Sociomaterial practices: Exploring technology at work. Organization Studies, 28(9), 1435-1448.

Orlikowski W. J., \& Scott S. V. (2008). Sociomateriality: Challenging the Separation of Technology, Work and Organization. The Academy of Management Annals, 2(1), 433-474.

Ravn Olesen B., \& Nordentoft H. M. (2016). Walking the talk? A Micro-Sociological Approach to the Co-production of Knowledge and Power in Action Research. IJAR - International Journal of Action Research, 9(1).

Reason P. (1999). Integrating action and reflection through co-operative inquiry. Management Learning, 30(2), 207.

Reason P., \& Bradbury H. (2001). Handbook of Action Research. London: Sage.

Reason P., \& Bradbury H. (2008). Handbook of Action Research. London: Sage.

Reason P., \& Torbert W. R. (2001). The action turn: Toward a transformational social science. Concepts and Transformation, 6(1), 1-37. 
Simpson C. (2012, August 24). The Deadly Tin Inside Your Smartphone. Bloomberg.Com.

Retrieved from https:/www.bloomberg.com/news/articles/2012-08-23/the-deadly-tin-insideyour-smartphone

Steffen W., Richardson K., Rockström J., Cornell S. E., Fetzer I., Bennett E. M., ... Sörlin S. (2015). Planetary boundaries: Guiding human development on a changing planet. Science, 347(6223), 1259855.

Suopajärvi T. (2017). Knowledge-making on 'ageing in a smart city' as socio-material power dynamics of participatory action research. Action Research, 15(4), 386-401.

Turkewitz J. (2017, December 22). Corporations Have Rights. Why Shouldn't Rivers? The New York Times. Retrieved from https://www.nytimes.com/2017/09/26/us/does-the-coloradoriver-have-rights-a-lawsuit-seeks-to-declare-it-a-person.html

Wilson P. A., Walsh E., \& Bush A. (2018). First Person Action Research in Complex Social Systems: three stories of praxis. IJAR - International Journal of Action Research, 14(1).

Zalasiewicz J., Williams M., Steffen W., \& Crutzen P. (2010). The new world of the Anthropocene. Environmental Science and Technology, 44(7), 2228-2231.

About the Authors

Stephen Allen is a lecturer in the Work, Employment, People and Organisations Division at Sheffield University Management School. By working at the intersections of ideas about reflexivity, sustainability and leadership, his research explores how people make sense of and take action for socio-ecological sustainabilities.

Judi Marshall is a professor emerita in Learning and Leadership in the Department of Organisations, Work \& Technology at Lancaster University Management School. Her interests include developing first person action research, gendering, finding form in academic writing and acting for change for sustainability.

\section{Authors' addresses}

Stephen Allen

Sheffield University Management School

Conduit Road, Sheffield, S10 1FL

United Kingdom

E-mail: stephen.allen@sheffield.ac.uk

Judi Marshall

Dept of Organisations, Work \& Technology

Lancaster University Management School

Lancaster LA1 4YX

United Kingdom

E-mail: judi.marshall@lancaster.ac.uk 